\title{
Padrões e jogos matemáticos
}

\author{
Dores Ferreira \\ doresferreira@iec.uminho.pt \\ LIBEC/CIFPEC, Instituto de Estudos da Criança da Universidade do Minho \\ Pedro Palhares \\ palhares@iec.uminho.pt \\ LIBEC/CIFPEC, Instituto de Estudos da Criança da Universidade do Minho \\ Jorge Nuno Silva \\ Faculdade de Ciências da Universidade de Lisboa \\ jnsilva@cal.berkeley.edu
}

Resumo: Um estudo realizado junto de alunos do $3 .^{\circ}$ ao $6 .^{\circ}$ ano de escolaridade permitiu verificar a existência de relação entre a força do jogador de xadrez e a capacidade de resolver problemas com padrões. Este resultado suscitou a curiosidade de verificar se essa relação se estenderia a outros jogos, como por exemplo os jogos matemáticos. Neste artigo apresentamos os resultados de um estudo envolvendo alunos do Ensino Básico participantes no Campeonato Nacional de Jogos Matemáticos, bem como o contexto que o originou. Nesse estudo procurava averiguar-se a existência de relação entre a capacidade de jogar jogos matemáticos e a capacidade de resolver problemas com padrões. Como resultado principal verificámos existir uma relação para os seguintes jogos: Semáforo, Hex e Amazonas.

Palavras-chave: Jogos matemáticos; padrões; Ensino Básico; xadrez; investigação correlacional; resolução de problemas.

\section{Introdução}

A Matemática é um ramo do conhecimento que se interessa pelo estudo das regularidades, sejam elas numéricas ou geométricas, o que lhe conferiu o título de "ciência dos padrões" (DEVLIN, 2002). Na realidade os padrões estão presentes no nosso quotidiano. Basta observarmos o meio circundante para encontrarmos os mais diversos padrões, desde o ciclo dia-noite à regularidade das nossas refeições ou ainda à geometria 
de algumas pavimentações de passeios ou do chão das casas, como as que podemos observar em Conímbriga.

O ensino da Matemática também se tem preocupado com o estudo de padrões, sendo disso exemplo a grande referência à procura e visualização de padrões no documento das Competências Essenciais para o Ensino Básico (DEB, 2001). Também os Principles and Standards for school mathematics apontam para a utilização de actividades que envolvam padrões no ensino e aprendizagem da Matemática, referindo que estas actividades devem ser facultadas aos alunos desde o Ensino Pré-escolar (NCTM, 1991).

Nos últimos anos assiste-se a uma maior preocupação com o ensino e aprendizagem da Matemática, principalmente no Ensino Básico. Esta preocupação resulta essencialmente do insucesso escolar que os alunos têm vindo a revelar na área de Matemática. Uma das medidas implementadas pelo Ministério da Educação para combater esse insucesso consiste no Programa de Formação Contínua para Professores do Ensino Básico na área de Matemática. Trata-se de um programa de formação que visa melhorar as condições de ensino e aprendizagem da Matemática bem como a valorização das competências dos professores que leccionam essa área. Nesse sentido, a Formação Contínua em Matemática para Professores do Ensino Básico tem como objectivos: a) Promover o trabalho cooperativo entre escolas, agrupamentos e instituições de ensino superior com formação inicial de professores; b) Aprofundar o conhecimento matemático, didáctico e curricular dos professores; c) Fomentar o gosto pela matemática; d) Incentivar e desenvolver a realização de experiências de desenvolvimento curricular (ME \& MCTES, 2005). Um dos temas abordados pelo grupo de formação de Braga, no âmbito do referido programa, consiste nos jogos implementados no Campeonato Nacional de Jogos Matemáticos, promovidos pela Associação Ludus. A abordagem deste tema fundamenta-se no facto de os jogos de estratégia serem um meio de desenvolver capacidades semelhantes às que os alunos desenvolvem e necessitam para a resolução de problemas (PALHARES \& GOMES, 2006). Acresce, ainda, que neste tipo de jogos e na resolução de problemas se utilizam estratégias semelhantes.

O interesse pelos jogos de estratégia, ou por determinados jogos de estratégia, não é de todo uma novidade. Grandes matemáticos do passado revelaram muito interesse por jogos, sendo o xadrez possivelmente aquele que mais interesse terá suscitado. O interesse dos matemáticos pelos jogos originou um novo ramo da matemática relacionado com a teoria dos jogos (NEUMANN, 1990), sendo van Neuman um dos grandes impulsionadores. 


\section{O jogo de xadrez e os padrões}

Em Portugal tem-se verificado um crescimento da prática do xadrez junto das camadas mais jovens, nomeadamente dos alunos do Ensino Básico. Este facto contribuiu para a realização de um estudo correlacional, onde se procurou averiguar a existência de relação entre a capacidade de jogar xadrez e a capacidade de resolver problemas que envolvam padrões. Os estudos correlacionais são indicados quando se pretende descobrir ou clarificar relações entre as variáveis quando não há ou há muito pouca investigação prévia sobre o assunto (COHEN \& MANION, 1989). Este estudo pretendia verificar a existência ou não de relação entre o jogo de xadrez e os padrões, no sentido de identificar a capacidade de resolver problemas envolvendo um determinado tipo de padrões, junto de jogadores de xadrez e não jogadores de xadrez. Ou seja, procurava verificar a relação entre a capacidade de identificar padrões e a capacidade de jogar xadrez. Simultaneamente, procurava estudar a relação entre estas capacidades e a idade, os anos de escolaridade, o género e a avaliação escolar a Matemática dos sujeitos envolvidos no estudo (FERREIRA \& PALHARES, 2007, 2008).

Neste estudo participaram 437 alunos do $3 .^{\circ}$ ao $6 .^{\circ}$ ano do Ensino Básico, xadrezistas e alunos com xadrez como desporto escolar de várias zonas do país. Para a recolha de dados foram utilizados um inquérito e um teste que foi construído e validado para o efeito. $\mathrm{O}$ inquérito recolheu os dados necessários à caracterização da amostra bem como dados pertinentes ao estudo, como as avaliações escolares a Matemática, se é ou não jogador, o ELO, a data de nascimento, o género e o ano de escolaridade. O teste, constituído por 24 problemas que envolviam padrões geométricos e numéricos, baseou-se na formulação de questões semelhantes às observadas noutros autores, nomeadamente nas colocadas por Krutetskii (1976). Baseou-se ainda nas conclusões do mesmo Krutetskii (Idem) que verificava existirem tipos de abordagem predominantemente lógico-verbal ou analítica, visual-pictórica ou geométrica e harmónica (que combina as duas anteriores).

O tratamento estatístico fez-se através do programa SPSS para Windows, versão 13.0, sendo utilizados diversos testes, adequados a cada caso. Para medir a consistência interna foi utilizou o Alpha de Cronbach uma vez que é referido como uma das medidas mais usadas (PESTANA \& GAGEIRO, 2000). Para testar a normalidade foi utilizado o teste de Kolmogorov-Smirnov. Para observar a correlação entre a capacidade de resolver 
problemas que envolvem padrões e o ELO dos jogadores foi utilizado o coeficiente de Pearson ( $r$ ), uma vez que para este grupo os dados eram paramétricos. Foram ainda utilizados o coeficiente de correlação point-biserial $\left(r_{\mathrm{pb}}\right)$, o coeficiente de correlação de Spearman, o de Kendall's Tau $(\tau)$, que apesar de não ser muito popular é considerado um teste robusto e o coeficiente de correlação parcial para verificar a correlação parcial entre a classificação total obtida no teste e o Elo controlada pela idade, ano de escolaridade, género e avaliação escolar a Matemática (FIELD, 2000). Na interpretação do coeficiente de correlação foi utilizado o critério proposto por Cohen e Manion (1989) e Fraenkel e Wallen, (1990): correlações com coeficiente entre 0,20 e 0,35 revelam uma pequena relação entre as variáveis e correlações com coeficiente entre 0,35 e 0,65 são muitas vezes encontradas em investigação educacional, podendo ter valor teórico e prático, dependendo do contexto.

A análise da prestação obtida no teste revelou que os xadrezistas foram os que melhor resolveram o teste, principalmente a segunda parte. Ou seja, os alunos xadrezistas identificaram melhor padrões do que os alunos que não jogam xadrez, principalmente padrões numéricos.

Como resultado principal verificou-se a existência de uma relação $(r=0,38)$ entre o jogo de xadrez e a capacidade de identificar padrões, sendo a relação de $r=0,320$ para os padrões geométricos e de $r=0,463$ para os padrões numéricos. Desta forma, concluiu-se que existe relação entre identificar padrões numéricos ou geométricos e a capacidade de jogar xadrez, sendo essa relação mais forte para o caso dos padrões numéricos (FERREIRA \& PALHARES, 2007, 2008).

Atendendo a que a capacidade de identificar padrões é uma capacidade matemática, podemos dizer que nesse estudo foi investigada a existência de relação entre um determinado jogo e uma determinada capacidade matemática. Gobet, de Voogt e Retschitzki (2004) referem que uma das fragilidades dos estudos sobre jogos de tabuleiro se prende com o facto de raramente se replicarem ou alargarem a outros jogos. O estudo referido apenas aborda o jogo de xadrez o que nos poderá levar a questionar se os resultados seriam idênticos para qualquer jogo de estratégia ou "jogo matemático", como referem Neto e Silva (2004). Este facto originou a realização de um estudo, junto dos finalistas do Campeonato Nacional de Jogos Matemáticos, na tentativa de verificar se para esses jogos se verificaria uma relação análoga à observada para o jogo de xadrez. Com este estudo pretendia verificar-se a existência de relação entre a resolução de problemas envolvendo padrões e os jogos de estratégia utilizados no Campeonato Nacional de Jogos 
Matemáticos. É de salientar que os jogos intervenientes neste campeonato são jogos de tabuleiro e jogos de informação perfeita, tal como o xadrez.

\section{Jogos Matemáticos}

O Campeonato Nacional de Jogos Matemáticos é um campeonato destinado a alunos do Ensino Básico e Secundário que se realiza anualmente desde 2005. Trata-se de uma iniciativa com o apoio da Associação Ludos, da Associação de Professores de Matemática, da Sociedade Portuguesa de Matemática e de outras entidades com o objectivo de divulgar e promover o interesse pelos jogos, nomeadamente pelos jogos matemáticos. Até à data realizaram-se três campeonatos, encontrando-se já disponível o regulamento para a edição de 2007/2008, cuja final se realizará no dia 29 de Fevereiro, na Universidade do Minho, em Braga. Em cada Campeonato têm sido utilizados seis jogos que são distribuídos pelos diferentes níveis de ensino. Desses seis jogos há quatro que se têm mantido constantes desde a primeira edição e que se manterão para a $4 .^{a}$ edição: Amazonas, Hex, Ouri e Pontos e Quadrados. Na primeira edição participaram também Jogos Poliédricos e Peões, nas edições seguintes estes jogos foram substituídos pelo Go e pelo Semáforo e, finalmente, na próxima edição o Go será substituído pelo Rastros. Os jogos utilizados nestes campeonatos têm a particularidade de serem jogos de estratégia, sem informação escondida nem a utilização de dados ou qualquer elemento que introduza a variável sorte nas jogadas. São por isso designados jogos matemáticos. Nestes jogos o resultado final é determinado pelas jogadas dos dois jogadores.

O Campeonato Nacional de Jogos Matemáticos tem envolvido um grande número de alunos de escolas de diferentes zonas do país. No ano lectivo de 2006/2007 participaram alunos provenientes de escolas de Vila Real, Lagos Porto Santo, Funchal, dando apenas alguns exemplos representativos das diferentes zonas do país, tendo-se verificado uma maior participação das escolas situadas nas zonas Centro/Sul. A final do Campeonato de Jogos Matemáticos de 2006 realizou-se em Évora com cerca de 900 jogadores inscritos. Os jogos utilizados na competição eram os seguintes: Pontos e Quadrados, Semáforo, Ouri, Hex, Amazonas e Go. Na tabela n. ${ }^{\circ} 1$ podemos verificar a sua distribuição pelos diferentes níveis de escolaridade. 


\begin{tabular}{|c|c|c|c|c|}
\hline \multirow{2}{*}{ Jogos } & \multicolumn{3}{|c|}{ Ensino Básico } & \multirow{2}{*}{$\begin{array}{c}\text { Ensino } \\
\text { Secundário }\end{array}$} \\
\hline & $\mathbf{1 .}^{\mathbf{0}}$ Ciclo & $\mathbf{2 .}^{\mathbf{0}}$ Ciclo & 3. $^{\mathbf{0}}$ Ciclo & \\
\hline Pontos e Quadrados & $\checkmark$ & & & \\
\hline Semáforo & $\checkmark$ & $\checkmark$ & & \\
\hline Ouri & $\checkmark$ & $\checkmark$ & $\checkmark$ & \\
\hline Hex & & $\checkmark$ & $\checkmark$ & $\checkmark$ \\
\hline Amazonas & & & $\checkmark$ & $\checkmark$ \\
\hline Go & & & & $\checkmark$ \\
\hline
\end{tabular}

Tabela n. ${ }^{\circ}$ 1: Jogos do $3 .{ }^{\circ}$ Campeonato Nacional de Jogos Matemáticos

\section{Desenvolvimento do estudo}

A recolha de dados para a realização de um estudo acerca da procura de relação entre os jogos e os padrões teve lugar em Évora, onde se realizou a final do Campeonato Nacional de Jogos Matemáticos, junto dos finalistas de cada jogo, com excepção do Go cujos jogadores são alunos do Ensino Secundário. Esta recolha de dados foi possível graças à excelente organização do campeonato e ao apoio prestado pela Comissão Organizadora, o que permitiu a aplicação de testes e questionários a um total de 64 jogadores.

A análise estatística foi realizada recorrendo ao programa SPSS para Windows.

Atendendo a que utilizámos o ranking das classificações finais dos jogadores, quanto menor o número da posição ocupada melhor a sua classificação. Desta forma, um coeficiente de correlação negativo indicaria que os jogadores melhor classificados teriam melhor prestação no teste.

Primeiramente testou-se a fiabilidade do teste para os alunos do $3 .^{\circ}$ Ciclo do Ensino Básico, utilizando o Alpha de Cronbach. Este teste estatístico permite-nos analisar a consistência interna dos itens. Sendo considerado aceitável um valor de 0,70 (FRAENKEL \& WALLEN, 1990), verifica-se, no entanto, referência a valores mais baixos (SANTOS, 1999; GEORGE \& MALLERY, 1995). Foram recolhidos os dados a uma amostra constituída por 30 indivíduos e verificou-se que o Alpha de Cronbach apresentava o valor 
de 0,678 , que considerámos aceitável. Para os restantes alunos a fiabilidade do teste já havia sido comprovada no estudo anteriormente realizado, apresentando o valor de 0,763 (FERREIRA \& PALHARES, 2007, 2008).

Seguidamente passaremos a relatar os resultados da análise de dados referente a cada jogo. Nessa análise foram considerados dois aspectos: o jogo e o nível de ensino.

\section{O Semáforo}

Analisando os jogadores de Semáforo pertencentes ao $1 .^{\circ}$ Ciclo do Ensino Básico verificámos que para este grupo de jogadores existe uma relação entre a capacidade de jogar Semáforo e a capacidade de identificar padrões, com um coeficiente de correlação de $(r=-0,757)$. Este valor indica uma boa correlação entre as duas variáveis (FRAENKEL \& WALLEN, 1990).

\begin{tabular}{|c|c|c|c|}
\hline \multicolumn{2}{|c|}{ Semáforo - $1 .^{\circ}$ Ciclo } & Ordem & Teste \\
\hline $\begin{array}{l}\text { Orde } \\
\mathrm{m}\end{array}$ & $\begin{array}{l}\text { Pearson } \\
\text { Correlation } \\
\text { Sig. (2-tailed) } \\
\text { N }\end{array}$ & 10 & $\begin{array}{r}-, 757\left(^{*}\right) \\
, 011 \\
10\end{array}$ \\
\hline Teste & $\begin{array}{l}\text { Pearson } \\
\text { Correlation } \\
\text { Sig. (2-tailed) } \\
\text { N }\end{array}$ & $\begin{array}{r}-, 757(*) \\
, 011 \\
10\end{array}$ & 10 \\
\hline
\end{tabular}

Tabela n. ${ }^{\circ}$ : Relação entre os jogadores de Semáforo do $1 .^{\circ}$ Ciclo e a capacidade de identificar padrões

\section{O Amazonas}

A recolha de dados, junto dos jogadores de Amazonas, apenas foi possível para os alunos do 3. ${ }^{\circ}$ Ciclo do Ensino Básico. Para este grupo, constituído por 11 alunos, verificouse a existência de relação entre a capacidade de jogar Amazonas e a capacidade de resolver problemas com padrões, com um valor de $r=-0,580$.

36 REVEMAT - Revista Eletrônica de Educação Matemática. V3.3, p.30-40, UFSC: 2008. 


\begin{tabular}{|ll|r|r|}
\hline \multicolumn{2}{|c|}{ Amazonas - 3. ${ }^{\mathbf{0}}$ Ciclo } & Ordem & \multicolumn{1}{c|}{ Teste } \\
\hline Orde & Pearson & 1 &,- 580 \\
& Correlation & &, 061 \\
& Sig. (2-tailed) & & 11 \\
& $\mathrm{~N}$ & 11 & 1 \\
\hline Teste & Pearson &,- 580 & \\
& Correlation & & \\
& Sig. (2-tailed) & 11 & 11 \\
& $\mathrm{~N}$ & 061 & \\
\hline
\end{tabular}

Tabela n. ${ }^{\circ}$ : Relação entre os jogadores de Amazonas do $3{ }^{\circ}$ Ciclo e a capacidade de identificar padrões

\section{Hex, Pontos e Quadrados, Ouri e Go}

No jogo Hex testaram-se os grupos de jogadores dos $2 .^{\circ}$ e $3 .^{\circ}$ Ciclos do Ensino Básico. Para o grupo do $3 .^{\circ}$ Ciclo apurou-se um coeficiente de correlação de $r=-0,580$, com o nível de significância de 0,203 e para o grupo do $2{ }^{\circ}$ Ciclo apurou-se um coeficiente de correlação de $r=0,570$, com um nível de significância de 0,316.

Para o jogo Pontos e Quadrados verificou-se um coeficiente de correlação de 0, 408 com o nível de significância de 0,364 para os jogadores do $1 .^{\circ}$ Ciclo do Ensino Básico. Relativamente ao Ouri obtivemos uma situação idêntica à obtida com o jogo Pontos e Quadrados, com um coeficiente de correlação de 0, 320 e um nível de significância de 0, 4 para os jogadores do 2. ${ }^{\circ}$ Ciclo do Ensino Básico.

Estes resultados não asseguram a existência de relação entre a capacidade de jogar os respectivos jogos e a capacidade de resolver problemas com padrões.

O jogo do Go não interveio no estudo uma vez que apenas participam os alunos do Ensino Secundário e o teste não se encontra validado para estes alunos. No entanto, é uma possibilidade a considerar num futuro estudo, pois o teste tem-se revelado muito abrangente ao ser validado para alunos do $3 .^{\circ}$ ao $9 .^{\circ}$ ano do Ensino Básico. 


\section{Conclusão}

Como resultado principal verificou-se a existência de uma relação entre a capacidade de jogar Semáforo e a capacidade de resolver problemas com padrões $(r=-$ 0,757) para os alunos do $1 .^{\circ}$ Ciclo do Ensino Básico. Este é um valor importante na medida em que o nível de significância é de 0,011.

O resultado obtido para os jogadores de Amazonas do 3. ${ }^{\circ}$ Ciclo do Ensino Básico é também um resultado com interesse analisar. Para este grupo de jogadores verificou-se uma correlação de $r=-0,58$ entre a capacidade de jogar Amazonas e a capacidade de resolver problemas com padrões com um nível de significância de 0,06. Este nível de significância apresenta-se muito próximo do nível de $p<0,05$ considerado aceitável.

Estes resultados revelam a existência de relação entre os respectivos jogos de estratégia e os padrões, com coeficientes de correlação superiores aos obtidos para o jogo de xadrez. No entanto, para que possamos obter resultados mais robustos torna-se necessário realizar um estudo exaustivo que envolva um número substancial de jogos e uma amostra com um número mais consistente.

Relativamente aos restantes jogos, verificou-se uma relação de $r=-0,580$, com o nível de significância de 0,203 para os jogadores de Hex do 3. ${ }^{\circ}$ Ciclo do Ensino Básico e de $r=0,570$, com um nível de significância de 0,316, para o grupo de jogadores do $2 .^{\circ}$ Ciclo do Ensino Básico; nos jogadores de Pontos e quadrados do $1 .^{\circ}$ Ciclo do Ensino Básico apurou-se uma correlação de 0,408, com o nível de significância de 0,364 e nos jogadores de Ouri do 2. ${ }^{\circ}$ Ciclo do Ensino Básico verificou-se uma relação de $r=0,320$ com um nível de significância de 0,4 .

O estudo realizado com os jogos do Campeonato Nacional de Jogos Matemáticos, apesar de ter alguma fragilidade devido ao número reduzido da amostra, não deixa de ser um indicador da necessidade de realizar um estudo aprofundado no sentido de apurar a relação entre os jogos matemáticos e os padrões.

Dos resultados apresentados emerge a necessidade de implementar mais estudos que permitam clarificar as vantagens da utilização de jogos no ensino e aprendizagem da matemática, nomeadamente da matemática elementar. 


\section{Referências}

COHEN, L. \& MANION, L. Research Methods in Education. 3. ed. London: Routledge, 1989.

DEB. Organização Curricular e Programas: Ensino Básico - $1 .{ }^{\circ}$ Ciclo. Lisboa: Editorial do Ministério da Educação, 1998.

DEB. Currículo nacional do ensino básico. Lisboa: Editorial do Ministério da Educação, 2001 .

DEVLIN, K. Matemática: a ciência dos padrões. Porto: Porto Editora, 2002.

FERREIRA, M. D. P. \& PALHARES, P. O jogo de xadrez e a identificação de padrões. Boletim da SPM, 56, pp. 93-112, Maio de 2007.

FERREIRA, M. D. P. \& PALHARES, P. (2007b). Chess and problem solving involving patterns. The Montana Enthusiast of Mathematics. Trabalho aceite para publicação, Junho de 2008

FIELD, A. Discovering Statistics using SPSS for Windows. London: Sage publications, 2000 .

FRAENKEL \& WALLEN. How to Design and Evaluate Research in Education. New York: Mc Graw-Hill, 1990.

GEORGE, D. \& MALLERY, P. SPSS/PC + Step by: A Simple Guide and Reference. Belmont: Wadsworth Publishing Company, 1995.

GOBet, F., VOOGT, A. \& RETSCHITZKI, J. Moves in Mind: the Psychology of Board games. Hove: Psychology Press, 2004.

KRUTETSKII, V. A. The psychology of mathematical abilities in schoolchildren. Chicago: Chicago University Press, 1976.

ME \& MCTES. Despacho conjunto n. ${ }^{\circ}$ 812/2005: DR II Série, n. 204 de 24 de Outubro de 2005 .

NCTM. Normas para o Currículo e a Avaliação em Matemática Escolar. Lisboa: APM \& IIE, 1991. 
NETO, J. P. \& SILVA, J. N. Jogos matemáticos, Jogos Abstractos. Lisboa: Gradiva, 2004.

NEUMANN, J. Theory of games and economic behaviour. Princeton: University Press, 1990.

PALHARES, P. \& GOMES, A. Mat1C: desafios para um novo rumo. Braga: IEC Universidade do Minho, 2006.

PESTANA, M. H. \& GAGEIRO, J. N. Análise de dados para ciências sociais - A complementaridade do SPSS. Lisboa: Edições Sílabo, 2000.

SANTOS, J. R. A. Cronbach's Alpha: A tool for Assessing the Reliability of Scales. Journal of Extension, 37 (2), 1999. 